
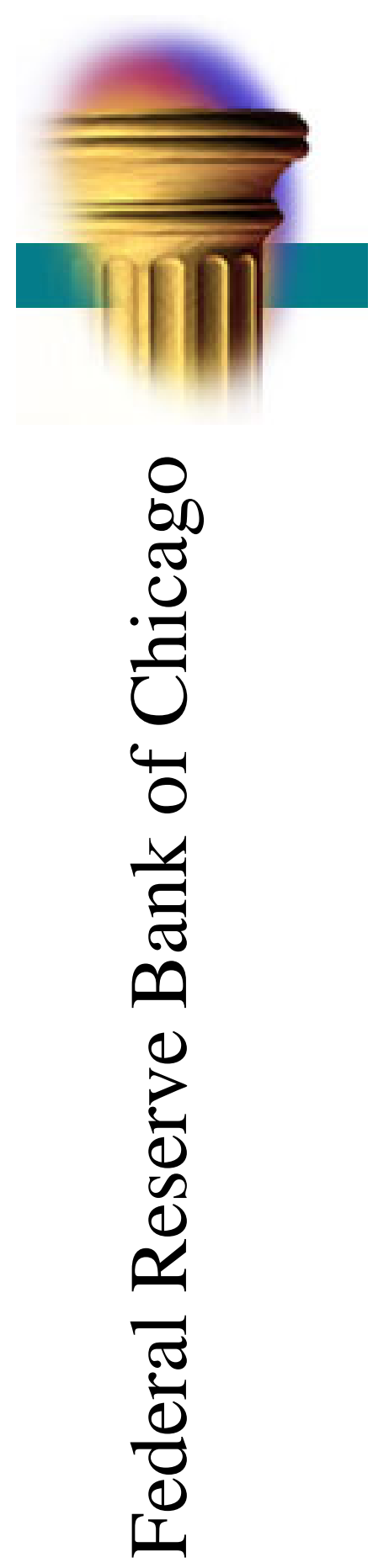

\title{
Credit Score Doctors
}

Luojia Hu, Xing Huang, and Andrei Simonov

\section{February 25, 2020}

\section{WP 2020-07}

https://doi.org/10.21033/wp-2020-07

${ }^{*}$ Working papers are not edited, and all opinions and errors are the responsibility of the author(s). The views expressed do not necessarily reflect the views of the Federal Reserve Bank of Chicago or the Federal Reserve System. 


\title{
Credit Score Doctors
}

\section{Luojia Hu, Xing Huang, Andrei Simonov ${ }^{\ddagger}$}

\author{
February 25, 2020
}

\begin{abstract}
We study how the existence of cutoffs in credit scores affects the behavior of homebuyers. Borrowers are more likely to purchase houses after their credit scores cross over a cutoff to qualify them for a higher credit score bin. However, the credit accounts of these individuals (crossover group) are more likely to become delinquent within four years following home purchases than the accounts of those who had stayed in the same bin (non-crossover group). The effect is not only concentrated in subprime bins, but in other bins as well. It is neither limited to pre-crisis period nor curtailed by postbust reforms. Using recent house price growth to proxy for the incentives for home purchases, we find that the gap in the delinquency rates between crossover and noncrossover groups is larger for areas with higher recent house price growth. Overall, our results indicate that the credit score at the time of home purchase may not be sufficiently informative because of individuals' strategic behavior, and suggest the importance of using the longer history of credit scores rather than just the latest draw in making lending decisions.
\end{abstract}

We would like to thank Ashley Wong and Sharada Dharmasankar for excellent research assistance. We also benefited from conversations and comments from Sumit Agarwal, Kenneth Brevoort (discussant), David Echeverry (discussant), Jim Goldman (discussant), Charles Hadlock, Michaela Pagel, Johannes Stroebel, Nancy Wallace, Jialan Wang (discussant), seminar and conference participants from Chicago Fed, National University of Singapore, University of Illinois at Chicago, MFA 2017, Early Career Women in Finance Conference, New Perspectives on Consumer Behavior in Credit and Payments Markets Conference (Philadelphia Fed), EFA 2019. The opinions expressed here are those of the authors and not necessarily those of the Federal Reserve Bank of Chicago or the Federal Reserve System. All errors are our own.

*Federal Reserve Bank of Chicago, lhu@frbchi.org

${ }^{\dagger}$ Washington University in St. Louis, Olin Business School, xing.huang@wustl.edu

${ }_{\ddagger}^{\ddagger}$ Michigan State University, Eli Broad College of Business, simonov@broad.msu.edu 
[Credit repair] service is the mortgage equivalent of cosmetic surgery. Using the tricks of the trade, they give [client's] credit report a face-lift, making it look better than it is. Artificially raising his score doesn't make him a better risk, it means he gets a loan with better terms.

Richard Bitner, "Confessions of a subprime lender", p.81.

\section{Introduction}

Credit score is, arguably, the most important number that affects a consumer's financial life. This role is partially driven by the changes in the industry (Stein (2002); Berger et al. (2005); Liberti and Mian (2009)), the rise of securitization (among others, Mian and Sufi (2009); Mian and Sufi (2011)), and the deeply set belief that credit score also measures the character of the borrower. ${ }^{1}$ It not only is used in granting credit, but also affects numerous non-credit outcomes of individuals. ${ }^{2}$

When individuals purchase houses, probably their largest investments, credit score is likely the single most important piece of financial information individuals have to get approved for a mortgage at the best interest rate. Given that both GSEs and banks routinely use cutoffs in both granting and pricing loans, we hypothesize that the mere existence of those cutoffs, coupled with the statutory requirement to use only current credit score, may create incentives for individuals to game the system and strategically behave in a way that makes credit scoring less informative. ${ }^{3}$ Anecdotal evidence shows that this type of strategic behavior is prevalent in the lending markets. For example, a casual online search for "credit score repair" generates about half a million results, which include information from both consulting companies and major business publications (Forbes, New York Times, CNBC). ${ }^{4}$

\footnotetext{
${ }^{1}$ For example, Toni Bowers mentioned that "[credit score] serves as a general measure of responsibility and organization" in the "Career Management" blog of September 24, 2006.

${ }^{2}$ For example, job applications (Bos, Breza, and Liberman (Forthcoming); Herkenhoff, Phillips, and Cohen-Cole (2017)), setting insurance rates, apartment rentals (Dunn and Grabchuk (2010)), cell phone contracts, even dating (https://www.bankrate.com/finance/consumer-index/survey-credit-scores-factor-indating.aspx).

${ }^{3}$ Relatedly, in the corporate setting, Begley (2015) shows that the financial ratio thresholds in the rating process of credit rating agencies may provide incentives for firms to distort their investments to affect credit ratings before bond issuance.

${ }^{4}$ One of the authors of this paper knows about credit manipulation from personal experience. As a new arrival to the US with a minimal credit score, he was asked by the real estate agent to borrow money using his clunker car as collateral. A series of three 5,000 dollars one-month loans from a major bank at high-interest rate brought the borrower up by more than 140 points to the FICO level of 745 . The whole process was facilitated by the real estate agent and bank loan officer (recommended, in turn, by the real
} 
While the services with the most public attention are aimed for the clientele with subprime credit, ${ }^{5}$ strategic behaviors are by no means limited to this group of homebuyers. Wall Street Journal reports that moving one's credit score from 750 to 770 could lower the interest rate about $0.18 \%$ as of January 2015 . This translates to a $\$ 13,366$ savings in interest over the life of a $\$ 400,000,30$-year fixed-rate mortgage with a $25 \%$ down payment. Savings on jumbo mortgages and car loans for borrowers in lower quality score categories are even greater. For example, a car buyer with a credit score of 730 could get a loan at an interest rate $3.6 \%$ higher than a borrower in the $800+$ range. In addition, multiple lenders report differential origination fees and lower points used. All the more concerning is how quickly one can improve credit scores: according to Ethan Dornhelm, principal scientist at Fair Isaac, the borrower score can be improved within as little as a month. ${ }^{6}$

This type of strategic behavior is not a problem if the individual's credit quality and the score improve together, so that the current score serves as a good indicator of a homebuyer's future default risk. However, if a divergence emerges between credit scores and default risks around home purchases, it may result in inefficient resource allocations. In his book, "Confessions of a Subprime Lender", Richard Bitner compares it to a face lift: it does not decrease the risk, but rather is designed to hide the real picture of an individual's credit risk. Building on these ideas, we ask the following question: do homebuyers behave strategically (either through building up scores or strategic timing) to obtain favorable credit scores for home purchases, leading to the discrepancy between credit scores and default risks? If so, that means that credit scores are prone to manipulation, and usefulness of the credit scores is limited.

We exploit data from the Federal Reserve Bank of New York's (FRBNY) Consumer Credit Panel (CCP), which is a panel data set collected by the credit bureau Equifax each quarter, beginning in 1999. The dataset tracks individuals' credit score, access to, and use of

estate agent).

${ }^{5}$ In 1990s, numerous abuses in credit repair industry ([T]he only thing that most credit repair clinics clean out are consumers checkbooks. see 136 CONG. REC. 18,766,1990) resulted in public outcry and adoption of the Credit Repair Organization Act of 1996. While the complaints about implementation of CROA are numerous (see Hanft (2011)), we abstract from those problems in our paper. Instead, we are interested in the effect of such services on mortgage markets.

${ }^{6}$ See the article on Wall Street Journal of Jan 9, 2015: http://www.wsj.com/articles/ how-to-perfect-your-credit-score-1420832973 
credit at a quarterly frequency, including extensive information about various loans or credit accounts. This includes information on mortgage accounts, home equity revolving accounts, auto loans, bank card accounts, student loans, and other loan accounts.

We start with showing that borrowers are more likely to purchase houses in the quarter after crossing over to a higher credit score bin than other quarters. The probability of purchasing a house given not previously owning one increases by 2.22 percentage points if individuals cross over credit score bins in the previous year. This effect is prevalent across all time periods. In addition, the effect of crossover is not a simple manifestation of the effect of the increase in scores, the effect of the increase in scores becomes stronger when crossover is involved.

If individuals deliberately change credit behaviors to build up their credit scores around the time of home purchases, or strategically time their home purchases when their scores change in their favor, credit scores may deviate from individuals' true credit quality at the time of home purchases. Next, we compare the credit quality (measured by the delinquency rates of credit accounts post-home purchase) between the crossover group and the noncrossover group. We find that the credit accounts of homebuyers who crossed over to the higher bin are more likely to become delinquent in the four years following purchase than those who had stayed in the same bin. The effect is strong for all risk groups (subprime, nearprime, and prime). For the subprime group, the incremental effect is about 19-33 percent (24.37\% for non-crossover borrowers vs $32.62 \%$ for crossover borrowers after one year, and $48.70 \%$ vs $58.00 \%$ after four years). The effect is even stronger for prime borrowers (around 66 percent since the first year after home purchases). However, among subprime borrowers the effect is front-loaded: the excess delinquency rate of the crossover group over the noncrossover group takes place largely in the first year, while delinquency rates peak three to four years after loan origination for prime borrowers. The results are quite robust and similar across all subperiods, with a stronger effect from 2004-2007, with the peak of housing prices and right before the recession.

In a multivariate regression framework, we also show that the differential delinquency rates between crossover and non-crossover borrowers remain significant after controlling for current credit score, state, year, and state by year fixed effects. The results are also robust 
controlling for Loan-to-Value (LTV) ratio, and excluding individuals with "predetermined" increases in credit score due to derogatory remarks removals.

One concern is that the results may be mechanical given the mean-reverting properties of credit scores: crossover individuals may experience a larger increase of credit scores in the past (which may be associated with a larger deviation from the credit quality) than the non-crossover individuals. Therefore, the crossover group may have higher delinquency rates after home purchases. We test this alternative story by controlling for the change in credit scores and interacting the crossover dummy with the change in credit scores. Our results show that the differential delinquency rates between the crossover and non-crossover groups exist above and beyond the change in scores. Moreover, the effects of the change in credit scores differ between the crossover and the non-crossover groups. A larger increase in credit score before home purchases increases delinquency rates, but the effect of the increase in credit score is much stronger for the crossover group, and decreases the delinquency rates for the non-crossover group.

Finally, to further support the credit score boosting hypothesis, we explore possible heterogeneities in incentives for strategic behavior. We first construct an incentive measure based on recent house price growth. To justify recent house price growth as an incentive proxy, we provide suggestive evidence that individuals' credit behaviors vary with incentives. We identify four types of active behaviors that may be employed to increase credit scores, two of which are prudent type (i.e. increasing credit score by improving credit quality) and two of which are strategic type (i.e. increasing credit score without improving credit quality). We find that individuals are more likely to exhibit the strategic behavior and less likely to exhibit the prudent behavior in markets with higher recent real estate appreciations.

We then investigate whether the incentives have differential impacts on the timing of individuals' house purchases after crossover, and on the discrepancy between credit scores and credit quality. For the cases where individuals have stronger incentives to purchase houses, we find that the increase in probability of purchasing houses after crossing over is larger, and the differential delinquency rates between the crossover and non-crossover groups are also larger. The heterogeneity analysis further supports that our results are mainly driven by individuals' strategic behavior. 
Taken together, our results contribute to the overall picture of the real estate markets. Strategic credit score-related behavior was employed by both mortgage originators and borrowers to improve lending positions of borrowers. It is important to note that our results are not only concentrated in the subprime group. We show that individuals in all credit bins employ this strategy to some extent. We do not take a strong stand on whether the strategic behavior is active boosting of credit scores before home purchases or actively timing home purchases when there is a noisy surge in credit scores. Having said that, given that credit score monitoring was not readily available for most of our sample period, it is not likely that consumers monitor their scores constantly, waiting for random fluctuations to bring their score above the next threshold. The fact that our results are stronger in areas with higher incentives, and the incentives are related to strategic behaviors, also suggests that our results are at least partially driven by individuals' strategic behavior on credit scores.

More importantly, our results are not concentrated within the 2004-2007 period. While the use of liars' and NINJA loans was duly contained post-crisis, the practice of credit score healing did not stop. In this sense, our study goes beyond documenting unethical behavior in the pre-recession period, and has current policy implications. Moreover, we argue that recent technological developments that make it easy to monitor one's credit score in real time at no monetary or credit cost make it easier for the average consumer to doctor his or her credit score. Before the Fair and Accurate Credit Transactions Act of 2003 that allowed customers one free credit report request per year, most customers could not see their report unless they actually applied for loans. In 2007, Washington Mutual was the first bank that offered TransUnion FICO score monitoring service to their credit cardholders. The Dodd-Frank Act of 2010 requires the disclosure of credit score and related information when a credit score is used in taking an adverse action or in risk-based pricing. Many financial institutions are now allowing their customers access to their FICO scores from one or two credit bureaus monthly, weekly, or in real time.

Our results call for changes in how lenders estimate borrower creditworthiness. It seems that current credit score should be used with the history of recent changes in credit score. Lenders should pay attention to strategies like opening and paying off new loans, and reducing utilization via increasing credit limits. At the same time, genuine reduction of debt via 
paying off old loans and reduction of credit cards balances should be rewarded.

Our study also points out the cost associated with mechanical use of credit score and pooled equilibrium that arises as a result. In each credit score bucket, there are both good borrowers who are legitimately qualified for a loan at specific terms, and crossover individuals who should not be qualified at the same terms. Presence of the latter imposes the cost on the former. Our back-of-the-envelope calculation shows that such cost is as high as 24-38 basis points per annum. On $\$ 100,000$ mortgage, this translates $\$ 7,100-\$ 11,200$ over the life of the loan.

We also contribute to the literature on hard information as a solution to lending institution agency problems. Lender internal organization and its affect on soft information, loan provision, and loan contractual terms have been the topic of intensive studies in recent literature. Among others, Stein (2002) and Berger et al. (2005) study how the internal organization of banks affects the collection of soft information, and its incorporation into loan terms. Stein (2002) argues that the magnitude of agency conflict between lending institutions and loan officers depends on the importance of soft information. As a result, banks prefer to move to hard information as their decision variable. Berger et al. (2005) supports this view by showing that banks are less willing to lend money for informationally intensive projects. Liberti and Mian (2009) shows that a more hierarchical structure leads to less soft information collection. Agarwal and Hauswald (2010) finds that borrower proximity is related to the use of soft information.

Garmaise (2015), Berg, Puri, and Rocholl (2013), and Rajan, Seru, and Vig (2015) are three papers that are most related to ours. In Garmaise (2015), borrowers misrepresent their assets to move just above the cut-off limit. Berg, Puri, and Rocholl (2013) shows that loan officers who are forced to rely only on hard information use multiple trials to move loans over cut-offs. As in Garmaise (2015), we concentrate on a particular form of misrepresentation: credit score misrepresentation, which allows borrowers to obtain loans at more favorable terms. Anecdotal evidence points to realtors and loan originators as the main sources of this misrepresentation. Rajan, Seru, and Vig (2015) shows that credit default models don't provide accurate forecasts in boom periods if they were calibrated under a pre-real estate boom set of variables and incentives. We go further, and say that the existence of static 
cutoff-based system leads to strategic behavior of the borrowers.

The remainder of the paper is organized as follows. Section 2 describes the data used and presents motivating evidence for the prevalence of score manipulations. Section 3 exploits the tiered pricing feature of mortgages and examines the relationship between the timing of house purchases and crossing over. Section 4 presents evidence on differential delinquency rates for the crossover vs non-crossover groups. Section 5 centers on particular strategies and incentives for strategic behaviors. Section 6 concludes.

\section{Data}

\subsection{FRBNY Consumer Credit Panel/Equifax Data}

The main data set we use for the empirical analysis is from the Federal Reserve Bank of New York's (FRBNY) Consumer Credit Panel (CCP). This is a panel data set collected by the credit bureau (Equifax) each quarter starting from the first quarter of 1999. The FRBNY collects credit bureau data for these individuals, including the history of credit score (Equifax risk score), mortgage and non-mortgage debt, collection agency records, and personal background information. Individuals in the panel are selected randomly from the U.S. population based on the last two digits of their Social Security number (SSN). ${ }^{7}$ This sampling methodology ensures that the $5 \%$ random sample reflects the current demography of the U.S. population with a credit history and SSN. ${ }^{8}$

In the main sample, we restrict the data to individuals who bought their first home between 2000Q1 and 2012Q4, and were at least 18 years old at the time of home purchase. We remove homebuyers with extremely low or high scores, as they are less likely to engage in strategic behavior due to high manipulation costs or low marginal benefits. Specifically, letting $\tau^{*}$ denote the quarter in which an individual purchased her first home, our main sample contains homebuyers whose credit scores were never below 450 or higher than 740 at any point between $\tau^{*}-4$ and $\tau^{*}-1$, as well as at the time of home purchase $\tau^{*}$.

\footnotetext{
${ }^{7}$ Individuals can only be selected into the sample if they have a credit record on file that includes their SSN. This means that as soon as a young adult with a randomly selected SSN opens the first line of credit (often around age 18), that person will be added to the Equifax data set. Deceased individuals are dropped from the data set.

${ }^{8}$ See Lee and van der Klaauw (2010) for an excellent introduction to the data set.
} 


\subsection{Other datasets}

Loan Performance and Lender Processing Services (LPS) Dataset. For robustness tests which control for loan characteristics, we use a smaller merged sample between $\mathrm{CCP}$ and the Loan Performance and Lender Processing Services (LPS) data. The Equifax Credit Risks Insight Servicing McDash (CRISM) database links individuals in the Equifax Consumer Credit Panel to the mortgage-level McDash servicing data (LPS) using a confidential and proprietary matching process.

CoreLogic Home Price Index (HPI). To proxy for individual's incentives to purchase house, we use recent house price growth before home purchases as a measure of expected growth in future housing prices (Agarwal, Hu, and Huang (2016)). CoreLogic home price indices are calculated using weighted repeat sales methodology on a monthly frequency, with January 2000 as the base month. For our analysis, we select data only for single family combined homes (including distressed sales).

\subsection{Cutoff Rules and Credit Score Bins}

In 1995, Fannie Mae and Freddie Mac adopted credit score as part of underwriting, making it indispensable in mortgage lending. The highly structured securitization process involves numerous rules that were meant to lower borrowers' credit risk, which were originally established by Fannie Mae and Freddie Mac in order to standardize the securitization process of lender's mortgage loans. As part of the algorithm, Fannie Mae and Freddie Mac use multiple cutoffs to determine appropriate buckets for risk, and the corresponding pricing.

The most prominent guideline is not to lend to borrowers with credit scores below 620 (Avery et al. (1996); Loesch (1996); Calomiris and Mason (1999); Capone (2002); Freddie Mac (2001)). While lenders can use their own discretion and do manual underwriting instead of using the Fannie Mae Desktop Underwriter system (Fannie Mae, 2006), the processing cost in an environment of thin margins for originators makes it prohibitive for lenders to step away from the standard path. ${ }^{9}$

Other cutoffs exist as well. The documentation of the CCP dataset also exploits cutoffs

\footnotetext{
${ }^{9}$ In our communications with lenders, we were given the estimate of two workdays for manual underwriting on a loan vs. 60-90 minutes for Desktop Underwriter system.
} 
680 and 740 (in addition to 620) to divide individuals into credit score bins: subprime (550-619), near-prime (620-679), and prime (680-739). To verify if these cutoffs are actually exploited by lenders, we examine the distribution of credit scores for homebuyers, and look for discontinuities. As Bubb and Kaufman (2009) suggests, no matter what is the reason for lenders to adopt the cutoff rule (either as a response to the rule set by securitizers or as a rational response to per-applicant fixed costs in screening), the adoption of the cutoff rule would predict discontinuities in lending rates around cutoffs. We find that the scores with discontinuities slightly vary over the years, but are mostly multiples of 20 points away from 620 (e.g. $620,640,660, \ldots$ ). It suggests that the three cutoffs used for our main tests may define bins broader than the ones actually exploited by lenders. The results remain similar if we apply a finer definition of the credit bins using cutoffs with 20 point gaps.

\subsection{Summary Statistics}

Table 1 reports summary statistics. Panel A shows the credit score change for householdquarter observations until the quarter of home purchases, as well as in the quarter of home purchases. Overall, the four-quarter change in score for the quarter of home purchases is higher than that for all the quarters leading up to it. The probability of crossing over from a lower risk score bin to a higher one within the past four quarters shows a similar pattern.

Panel B focuses on two types of credit behaviors: the change in credit card utilization and the change in personal loan accounts in the 1 to 2 years before home purchase. The change in the number of credit cards with utilization rate $\geq 75 \%$ is the difference in the average number of open bankcard accounts with balance $\geq 75 \%$ of the credit limit from $\tau^{*}-4$ to $\tau^{*}-1$ and from $\tau^{*}-8$ to $\tau^{*}-5 .{ }^{10}$ Change in credit card balances is the difference in the average total bankcard balance from $\tau^{*}-4$ to $\tau^{*}-1$ and from $\tau^{*}-8$ to $\tau^{*}-5$. We restrict the sample to those who had nonzero credit balances in both periods. On average, homebuyers slightly increased utilization rates and carried higher balances on their cards,

\footnotetext{
${ }^{10}$ Note that the individual card utilization rate differs from the aggregate utilization rate (defined as the ratio of total balance to total limit). The dataset does not contain detailed information about the individual card utilization rate, but it provides the number of credit cards with high utilization (e.g. $\geq 75 \%$ ). We prefer this measure to the aggregate utilization rate because the latter may not capture strategic allocations across cards - one could redistribute expenses across cards to make sure the utilization rate of every card below certain cutoff without lowering the aggregate utilization.
} 
but there are considerable cross-sectional variations in these behaviors, especially the latter, which is evidenced by a large standard deviation and a large interquartile range. Number of newly taken loans is the total number of positive changes in consumer finance trades between each consecutive quarter from $\tau^{*}-4$ to $\tau^{*}-1$. Number of newly paid-off loans is the total number of negative changes in consumer finance trades between each consecutive quarter in the period from $\tau^{*}-4$ to $\tau^{*}-1$. The distributions of the number of newly taken loans and the number of paid-off loans are both highly skewed. A small number of individuals are very active in taking out and paying off loans before the home purchase.

In Panel $\mathrm{C}$, we focus on the delinquency rate, an important measure for default risks. Homebuyers are defined to be delinquent in a given period if there is at least one trade in the auto finance, auto bank loans, bank cards, consumer finance, first mortgage, home equity installment or revolving trades, student loans, or other trades categories; the trades also must be 90 days past due, 120 days past due, in collections, severely derogatory, or bankrupt. This panel reports the cumulative delinquency rate by credit score bin in quarters $\left[\tau^{*}+1, \tau^{*}+4\right]$, $\left[\tau^{*}+1, \tau^{*}+8\right],\left[\tau^{*}+1, \tau^{*}+12\right]$, and $\left[\tau^{*}+1, \tau^{*}+16\right]$. Consistent with lower credit scores indicating higher default risks, the subprime group has higher delinquency rates than the near-prime and prime groups across the board. Moreover, the subprime group starts to experience delinquency sooner than the other two groups after home purchase.

\subsection{Motivating Evidence}

Evidence shows that getting a higher credit score can really pay off for home buyers. First, a higher credit score can increase mortgage credit availability for prospective buyers. A recent paper by Anenberg et al. (2016) shows that mortgage credit availability is an increasing function in FICO scores, and the increase is sharpest in the (roughly) 580-650 range. Second, home buyers with higher credit scores could benefit from lower interest rates. Using a merged sample between the CCP data and the Loan Performance and Lender Processing Services (LPS) data, Table A.1 shows that interest rates decrease by about 0.20.4 percentage points as individuals move up from a lower credit score bin to the next credit score bin. This pattern is robust controlling for LTV ratio (as individuals in higher credit score bins may have lower LTV ratios, which could lower interest rates) and state-year fixed 
effects. A back-of-the-envelope calculation suggests that such one point differences in scores may cost individuals thousands of dollars in interest charges.

To examine if credit scores affect the decision of an individual's home purchase behavior, we conduct an exercise comparing the dynamics of credit scores between homebuyers and non-buyers in comparable periods. Specifically, we examine the credit score evolution of homebuyers around the time of the purchase with that of non-homebuyers who had similar scores as the buyers prior to purchase. For home buyer $i$, we identify the quarter $\tau_{i}^{*}$ she initiates her first mortgage account. We then match the buyer with a non-homebuyer who has the same credit score, the same age, is in the same state as home buyer $i$ in quarter $\tau_{i}^{*}-4$, and will not purchase a house in the next eight quarters. ${ }^{11}$ Figure 1 plots the average credit scores of home buyers and the matched non-homebuyers between $\tau_{i}^{*}-4$ and $\tau_{i}^{*}+4$. We show the comparison for three sub-periods: (1) 2000Q1 to 2003Q4; (2) 2004Q1 to 2007Q4; (3) 2008Q1 to 2011Q4, which naturally splits our sample into three equal-length periods, as well as separates the period after the peak of recent housing prices and the start of the most recent recession. In the interest of space, we only present the group of individuals whose credit scores were in the subprime group at $\tau_{i}^{*}-4$; the other two groups, near-prime and prime, show similar patterns.

Starting from a given bin at $\tau_{i}^{*}-4$, the credit scores of home buyers and non-homebuyers evolve quite differently over the next 2 years. The credit scores of home buyers increase by a large amount before home purchase and experience sharp declines afterwards, while the credit scores of non-homebuyers are substantially flatter. This striking contrast provides suggestive evidence that individuals may have strategically built up their credit scores prior to purchasing their house. This may result in a discrepancy between the credit score and the underlying credit quality in the short run. If the individual's credit quality is temporarily overrated, then her credit score is likely to revert after the home purchase. Interestingly, in all three sub-periods, the buyers' credit scores peak one quarter after the home purchase and then start to decrease. This evidence is consistent with mortgage originators' incentive to avoid loan delinquency in the first three months, because originators typically agree to

\footnotetext{
${ }^{11}$ To make sure that an individual is not counted as both a home buyer and a non-homebuyer during any quarter, we remove prospective buyers (who will purchase houses between $\tau_{i}^{*}-4$ and $\tau_{i}^{*}+4$ ) from the non-homebuyer group.
} 
repurchase any loan that misses a payment within the first three months according to the early payment default provision.

\section{Home Purchases and Crossover}

Most lenders practice tiered pricing. Interest rates remain the same within a tier but differ across them, and mortgage credit availability may also differ across tiers. Therefore, tiered pricing provides huge incentives for individuals to "cross over" these cutoffs. If individuals actively boosted their scores or strategically timed their scores for home purchases, they are more likely to buy houses right after crossing over the cutoffs. In this section, we will exploit the tiered pricing feature of mortgages, and examine individuals' timing of house purchases around crossover.

We use a simple discrete-time hazard specification to model the probability of home purchases, with the CCP individual-level data. Specifically, we use a Probit model for the binary outcome of home purchase (conditional on not previously owning a home). The latent variable is

$$
y_{i t}^{*}=\alpha+\text { srossover }_{i, t}+X_{i t}^{\prime} \Gamma+\epsilon_{i t}
$$

where $i$ indexes individual. The main independent variable, crossover $_{i, t}$, is an indicator variable which equals one if the credit score bin at quarter $t-4$ is lower than the credit score bin at quarter $t$. A set of fixed effects (e.g., age effect, state effect, year effect, or state times year effect) are included. We also include the credit score at quarter $t$ and its quadratic form as control variables for the current credit quality of the individual. The hazard rate for an individual's home purchase is then

$$
h_{i t}=\operatorname{Pr}\left(\text { Buy }_{i t}=1 \mid \text { Buy }_{i \tau}=0, \tau<t\right)=\operatorname{Pr}\left(y_{i t}^{*}>0\right)=\Phi\left(\alpha+\text { _rossover }_{i, t}+X_{i t}^{\prime} \Gamma\right)
$$

where $\Phi(\cdot)$ is the CDF of a standard normal distribution. The individuals are dropped from the sample after home purchases. Table 2 reports the marginal effects of crossing over. As Col (1) shows, generally speaking, crossing over to a higher credit score bin has a significantly positive effect on the probability of home purchases. The probability of purchasing a house given not previously owning one increases by 2.38 percentage points (pps) if individuals 
crossed over credit score bins in the past four quarters. This effect is robust to different sets of fixed effects and is prevalent across all time periods, with relatively smaller magnitude (1.06 pps) from 2000Q1 to 2003Q4 and relatively larger magnitudes (3.66 pps and 4.04 pps) for the other two periods (2004Q1-2007Q4 and 2008Q1-2011Q4).

This result suggests that individuals' timing of house purchases is closely related to when they cross over a credit score bin cutoff. One concern is that individuals who crossed over in the past four quarters may be the ones with higher recent changes in scores. It may be higher recent change in score rather than crossing over to a higher bin that drives home purchases. To show the important role of tiered pricing, we interact the crossover dummy with the change in credit scores, and also include the main effect of the change in credit scores. If the tiered pricing does not affect individual's home purchase behavior, and the crossover dummy is merely a proxy for the change in scores, we would expect the effect of change in scores to be the same no matter whether the change in scores involves crossing over to a higher credit score bin or not.

Specifically, we define the latent variable for the hazard rate of an individual's home purchase as:

$y_{i t}^{*}=\alpha+\beta_{1}$ crossover $_{i, t}+\beta_{2} \Delta$ riskscore $_{i, t-4, t}+\beta_{3}$ crossover $_{i, t} \times \Delta$ riskscore $_{i, t-4, t}+X_{i t}^{\prime} \Gamma+\epsilon_{i t}$

Table 3 shows that the effects of the change in credit scores are different between the crossover and the non-crossover group. Individuals are more likely to purchase a house when the recent change in credit scores is larger and the increase in scores lead to crossover to a higher credit score bin. However, if the increase in score happens within the same credit score bin (i.e., there is no crossover), it does not affect the likelihood of home purchase. The result implies that the tiered pricing plays an important role in affecting the timing of an individual's home purchases. The evidence that the effect of change in scores on the probability of home purchases is stronger for the crossover group also suggests that the effect of crossover on home purchases may not come from individuals manipulating their scores precisely around the cutoffs. If individuals precisely manipulate their scores around the cutoff and purchase houses right after they crossover, we would expect the probability 
of home purchases decreases with the change in scores, because if manipulation is costly, individuals who manipulate would attempt to cross over with changes in scores as small as possible.

\section{Credit Quality after Home Purchases}

In the following analysis, we compare the credit quality following home purchase between the crossover and the non-crossover group. We examine whether individuals in the crossover group have a larger discrepancy between the reported credit scores and underlying creditworthiness than individuals in the non-crossover group (i.e., individuals who have stayed in the same credit score bin before home purchases). We strive to separate the following two hypotheses:

1. Good citizen hypothesis: prospective homebuyers' credit scores move up prior to their home purchases, and their credit quality improves with their credit scores. Under this hypothesis, the current credit scores still serve as a good indicator of a homebuyer's future default risk.

2. Cosmetic surgery hypothesis: prospective homebuyers strategically increase their scores or time their home purchases with favorable credit scores, and there is a divergence between their credit scores and default risks. Under this hypothesis, we would expect that their scores deteriorate after the home purchase and revert back to the true level; also, they will be more likely to become delinquent afterwards than the non-crossover group with similar scores at the time of home purchases.

\subsection{Credit Score after Home Purchases}

Figure 2 plots the post-home purchase credit scores for the crossover and the noncrossover groups. Both groups are in the near-prime bin when they purchase their houses. The crossover group represents home buyers who moved up from lower bins (e.g. subprime bin) during the past four quarters before home purchase, and the non-crossover group represents homebuyers who stayed in the near-prime bin for at least four quarters before home purchase. We find that the post-purchase credit scores for these two groups of buyers move in opposite directions - while the non-crossover home buyers' scores increased slightly and 
stayed high 1 year after the purchase, the crossover buyers' scores drifted down continuously to levels lower than before the purchase. The evidence suggests that home buyers who have artificially boosted their scores to cross the cutoff are likely to have overrated credit quality; in the long run, their scores decrease and revert back to the true level. Indeed, it is interesting to note that the post-purchase reversal in home buyers' credit scores observed in Figure 1 is mainly driven by the behavior of the crossover group.

\subsection{Delinquency Rate after Home Purchases}

Another measure of credit quality that is of particular interest to lenders is the delinquency rate. We compare the delinquency rates between the crossover and non-crossover groups after their home purchases. As mentioned in Section 2, a home buyer is defined to be delinquent in a given period if there is at least one trade in any of the following categories: auto finance, auto bank loans, bank cards, consumer finance, first mortgage, home equity installment or revolving trades, student loans, or other trades, that is considered 90 days past due, 120 days past due, in collections, severely derogatory, or bankrupt. We consider delinquency in a broad set of credit accounts instead of just mortgage-related accounts, because (1) the delinquency in mortgage-related accounts is sparse, which adds noise to the estimation, and (2) individuals may strategically select the order of accounts to become delinquent, and delinquency in a broad set can better proxy for individuals' overall credit quality. We also consider the delinquency rate of mortgages in Section 4.2.3 and the results remain the same.

\subsubsection{Main results}

Table 4 shows the cumulative delinquency rate for one-year to four-year periods following home purchase. We report the comparison between the crossover and non-crossover groups separately for three current credit score bins (subprime, near-prime and prime). For all three bins, the crossover group shows higher delinquency rates than the non-crossover group, in as early as the first year after the home purchase. Crossover individuals appear to have lower credit quality than non-crossover individuals, although both groups are likely to obtain the same terms for their mortgages. We also observe different dynamic patterns across these three score bins. For the subprime bin, the excess delinquency rate of the crossover 
group over the non-crossover group largely takes place in the first year. Specifically, $88.7 \%$ $(=8.25 \% / 9.3 \%)$ of the long-term excess delinquency rate appears in the first year. In contrast, the wedge between crossover and non-crossover expands much more gradually for the nearprime and prime bins - the first year only accounts for $34.2 \%$ and $18.6 \%$ of the long-term excess delinquency rate, for the near prime and prime bins, respectively. In general, the results are quite robust across all subperiods, with a stronger effect during the 2004Q12007Q4 subperiod, with the peak of housing prices and right before the recession. Specifically, the long-term effects (the difference between crossover and non-crossover within four years after home purchases) are much larger for the near prime bin and the prime bin during the second subperiod.

We then extend the analysis to a multivariate framework, controlling for various fixed effects, such as the age effect, the state effect, the home purchase year effect, or the state by purchase year effect. The dependent variable is an indicator that takes a value of 1 if the individual is delinquent (as defined above) in the two years after home purchase. We choose the two-year period because credit scores estimate the risk of future delinquency over the next two years. We also include the credit score at quarter $t$ and its quadratic form as control variables for current credit quality of the individual.

Table 5 shows the results. We can see that current credit score is far from a sufficient statistic of individuals' credit quality. After controlling for the current score and its quadratic form, we find a positive and significant coefficient on the crossover variable - individuals in the crossover group have significantly higher delinquency rates 2 years after home purchases than those in the non-crossover group who were in the same score bin at the time of home purchases. In addition, the results are quite robust across all subperiods, and the coefficients on the crossover dummy are also larger in magnitude during the second subperiod relative to the other two. It is consistent with the cosmetic surgery hypothesis: individuals may have actively built up their credit scores right before home purchases or strategically timed their home purchases, which makes the current scores less informative about individuals' underlying creditworthiness.

One confounding effect is the mean-reverting feature of credit scores. If crossover individuals experience a larger increase of credit scores in the past, given the mean-reverting 
feature of credit scores, the crossover group may experience a larger decrease in credit scores and higher delinquency rates following the home purchases. To test if this story is true, we interact the crossover dummy with the change in credit scores, and also include the main effect of the change in credit scores. The results in Table 6 show that the effects of the change in credit scores are different between the crossover group and the non-crossover group. The increase in credit scores before home purchases relates to a higher delinquency rate for the non-crossover group, which is consistent with the mean-reverting of credit scores. However, the effect becomes much stronger for the crossover group. The results show that meanreverting credit scores are not likely to explain the coefficients on the crossover dummy; otherwise, we should observe the effects of the change in credit scores on delinquency rates have similar magnitudes for both groups.

\subsubsection{Robustness tests}

One concern is that crossover may be correlated with loan characteristics (e.g. LTV ratio) which matters for post-purchase delinquency rate. For example, individuals in the crossover group may use higher leverage (i.e. higher LTV ratio) than those in the noncrossover group (as shown in Table A.2), and higher leverage results in higher post-purchase delinquency rate. Even though the current credit score of individuals in the crossover group may fully reflect the credit quality of the individuals, we may still observe the positive relationship between crossover and post-purchase delinquency rate because of the omitted controls for loan characteristics. Since the CCP data does not contain information about loan characteristics, we rely on a smaller merged sample with the Loan Performance and Lender Processing Services (LPS) data to control for loan characteristics. As Table 7 shows, the loan-to-value ratio is indeed positively related to post-purchase delinquency rate, but more importantly, the effect of crossover is robust after controlling for the loan-to-value ratio.

We also conduct a robustness check by removing the individuals who have ever had a bankruptcy flag in our sample period. According to Dobbie et al. (2017), the removal of bankruptcy and charge-off flags results in increased credit scores, which are associated with increases in the number of credit card lines, credit card limits, and credit card balances. It is possible that the removal of bankruptcy flag is a common shock which leads to crossover, 
home purchase, and higher delinquency rate. To address this concern, we simply remove all individuals who have ever had a bankruptcy flag in our sample period from our analysis. As shown in Table A.3 and A.4, the results remain the same.

\subsubsection{Discussion}

So far, we use the delinquency rate in a broad sense. Though the credit score is supposed to be informative about individuals' credit quality, only the delinquency rate of mortgages matters for the banks who lend to individuals for house purchases. If the discrepancy between credit scores and credit quality only appears for credit accounts other than mortgages, it may still be rational for banks to apply tiered pricing and focus on current credit scores. Table 8 replaces the dependent variable in Table 5 with an indicator variable which equals one if the mortgage account (instead of any credit account) becomes delinquent in the two year period after home purchase. The coefficient on the crossover dummy is positive and statistically significant. The magnitude is slightly smaller due to less frequent delinquent events in mortgage accounts. The results suggest that, even from the bank's perspective, the credit risks of the crossover group and the non-crossover group are different but are priced the same.

\section{Incentive and strategic behavior}

To further examine the cosmetic surgery hypothesis, we explore possible heterogeneity in incentives for strategic behavior. We hypothesize that when individuals have higher expectations on future house prices, they have higher incentives to purchase house and hence strategically boost credit scores or time their purchases. If the incentives have differential impacts on the timing of individuals' house purchases after crossover, and on the discrepancy between credit scores and credit quality, it would further support that prospective homebuyers have strategic behavior on their credit scores around home purchases, which leads to a divergence between their credit scores and default risks. It also helps alleviate the aforementioned concern of mean reversion, because random shocks in credit scores should not vary with the incentives. 


\subsection{Incentive measure}

We proxy for individuals' future house price expectations by recent house price growth. Case and Shiller (2003) and Case, Shiller, and Thompson (2012) document that the expectations of future housing price appreciation are driven, among other factors, by the past increase in housing prices. Kuchler and Zafar (2019) document that individuals extrapolate from past home price changes when they form subjective expectations on future home price. ${ }^{12}$ The extrapolative expectations in the housing market may directly affect individual's house purchase behavior. ${ }^{13}$, or work through the channel of originators who have expectations of higher future price growth may become more aggressive to extend credits to borrowers or even help borrowers build up scores to meet the minimum score requirement. Another reason that recent house price growth could proxy for incentives for strategic behavior is that houses may be more expensive in areas with higher recent house price growth. With a more expensive house, the terms of the mortgage in interest rate and down payment matter more for the costs, which also increases the incentives for individuals to strategically boost their credit scores or time their purchases.

We use the CoreLogic home price index (HPI) data to compare housing price growth in different regions, as a measure of expected growth in future housing prices (Agarwal, Hu, and Huang (2016)). We use HPI data calculated at the CBSA level to capture variation in price growth between different metropolitan areas across the country. ${ }^{14}$ Specifically, we first calculate the average HPI at year $t$ in city $c$ as the 12-month average of the monthly HPI from CoreLogic. We then compute the annual growth rate of HPI from year $t-1$ to year $t$ as $\gamma_{c, t}=\frac{p_{c, t}-p_{c, t-1}}{p_{c, t-1}}$. We then smooth the house price growth by taking the average of HPI growth over the most recent three years as $\delta_{c, t}=\frac{1}{3} \sum_{k=0}^{2} \gamma_{c, t-k}$.

\footnotetext{
${ }^{12}$ Extrapolative expectations have been documented in other settings as well, for example, Greenwood and Shleifer (2019) and Da, Huang, and Jin (2019) for stock market, Koijen, Schmeling, and Vrugt (2015) for currencies and fixed income, etc.

${ }^{13}$ For example, Agarwal, Hu, and Huang (2016) find consistent evidence with a life-cycle housing-demand model in which high past price growth leads to expectations of high future price growth and thus accelerates home purchases at young ages.

${ }^{14}$ Within a given CBSA, HPI growth varies over time - the average range (High-Low) of HPI growth across all CBSAs is 21 percentage points. More importantly, this range also varies quite a bit across CBSAs. For example, while the annual HPI growth rate changed by no more than 13 percentage points over the period in the quarter of cities with lowest HPI growth rate, it swung by 25 percentage points or more in the quarter of cities with highest HPI growth rate.
} 


\subsection{Credit Behaviors and Incentives}

To justify the recent house price growth as an incentive proxy, we relate it to individual credit behavior. In Appendix Section A.1, we identify a set of credit behaviors that

predict the increase in credit scores in the short term. Among multiple ways individuals could improve their credit scores, we focus on credit card utilization rates and personal loan repayments.

We sort the CBSA level 3-year average house price growth into quartile groups, and examine how different active behaviors vary across the quartiles. Table 9 reports the results. Columns (1) and (2) show the probability of paying off loans during pre-purchase period, through taking new loans ( $\mathrm{Col}(1))$ or without taking new loans ( $\mathrm{Col}(2))$. Columns (3) and (4) show the probability of reducing credit card utilization rates, without increasing credit limit ( $\mathrm{Col}(3))$ or by increasing credit limit ( $\mathrm{Col}(4))$. Among these four behaviors, Columns (2) and (3) appear to be the prudent types of behaviors, while Columns (1) and (4) relate to the cosmetic types of behaviors. Consistent with our hypothesis, individuals in areas with higher house price growths are more likely to boost credit scores through cosmetictype strategic behaviors rather than through prudent behaviors. For example, if prospective home buyers in cities with the highest quartile house price growth want to improve their credit scores prior to the purchase, they are less likely to achieve the goal by purely reducing balances to reduce credit card utilization rate $(-2.88 \%)$ or repaying loans with savings ($6.18 \%$ ), but more likely do so by increasing credit limits or other methods to reduce credit card utilization rate $(6.25 \%)$ or taking out new loans to repay old loans $(3.17 \%)$, relative to those in cities with slow house price growth. The striking contrast between strategic and prudent behaviors justifies the use of house price growths as a proxy for strategic incentives.

\subsection{Home Purchases, Delinquency Rate and Incentives}

According to results shown in Section 4, individuals are more likely to purchase houses after crossing over to a higher credit score bin, and the crossover group has higher delinquency rates than the non-crossover group. If individuals have greater incentives to boost their credit scores for home purchases or strategically time their home purchases, then the timing of house purchases will be more highly related to crossing over. Crossover is more likely to 
create a gap between credit scores and credit quality, meaning that the excess delinquency rate of the crossover group would likely to be larger. We test these hypotheses in Tables 10 and 11 , by comparing the coefficient on the crossover dummy between the groups in the top and bottom quartile of house price growth. Specifically, we only keep individuals from the top and bottom quartile price growth distribution, and add an interaction term between the crossover and the top quartile.

The results in Table 10 shows that the increase in the likelihood of house purchases after crossover is significantly larger in the top HPI growth quartile than in the bottom HPI growth quartile. As for the heterogeneous impact of crossover on delinquency rates, the results in Table 11 show that the coefficient on the interaction term is positive and statistically significant. This means that while the delinquency rate of the crossover group is $1.05 \%$ higher than that of the non-crossover group in cities with slowest house price growths, the difference increases to about $1.9 \%(=1.05 \%+0.85 \%)$ in cities with highest price house growths. These results provide further support for the notion that the crossover is at least partially from strategic behaviors; otherwise, the gap in the delinquency rate between the crossover and the non-crossover groups would not be related to the incentives for strategic behaviors.

\section{Conclusion}

The eligibility and the terms of mortgages highly depend on homebuyers' credit scores around the time of the purchase, which provides prospective homebuyers great incentives to boost their scores. This is not a problem if the individual's credit quality and score improve together so that the current score still serves as a good indicator of homebuyer's future default risk. However, if prospective homebuyers strategically build up their scores around home purchases, a divergence could emerge between their credit scores and default risks, which may result in inefficiency in resource allocations.

In this paper, we use the CCP data and find evidence that, in the environment of a housing boom, many consumers resort to strategic behaviors to boost credit scores, such as repaying previous loans with newly taken loans or reducing credit card utilization rates by increasing credit card limits. Individuals who actively boost their scores are more likely to 
crossover to the next credit score bin (i.e. obtain better loan terms), and are more likely to purchase houses within the next quarter. However, the credit accounts of those individuals are more likely to become delinquent within four years after home purchase. We do not have any data to pin this behavior on mortgage originators, although anecdotal evidence suggests that credit score clinics were part of the service offered by mortgage originators during the recent housing cycle.

Our findings suggest that credit scores around home purchases become less informative due to home buyer's active boosting of credit scores. Lenders should consider not just the credit score bin which a borrower is currently in, but also the path by which she ends up there. For example, it would be reasonable to require not only that a borrower's current credit score satisfies certain conditions (e.g. exceeding 620), but also that it has been the case for a considerable period of time. While this would not completely eliminate the appeal of strategic behavior, it's likely to make it less prevalent. 


\section{References}

Agarwal, S., and R. Hauswald. 2010. Distance and private information in lending. Review of Financial Studies 23:2757-88.

Agarwal, S., L. Hu, and X. Huang. 2016. Rushing into american dream? house prices growth and the timing of homeownership. Review of Finance 20:2183-218.

Anenberg, E., A. Hizmo, E. Kung, and R. Molloy. 2016. The effect of mortgage credit availability on house prices and construction: evidence from a frontier estimation approach. Working Paper.

Avery, R., R. Bostic, P. Calem, and G. Canner. 1996. Credit risk, credit scoring and the performance of home mortgages. Federal Reserve Bulletin 82:621-48.

Begley, T. 2015. The real costs of corporate credit ratings. Working Paper .

Berg, T., M. Puri, and J. Rocholl. 2013. Loan officer incentives and the limits of hard information. NBER working paper series .

Berger, A. N., N. H. Miller, M. A. Petersen, R. G. Rajan, and J. C. Stein. 2005. Does function follow organizational form? evidence from the lending practices of large and small banks. Journal of Financial Economics 76:237-69.

Bos, M., E. Breza, and A. Liberman. Forthcoming. The labor market effects of credit market information. Review of Financial Studies .

Bubb, R., and A. Kaufman. 2009. Securitization and moral hazard: Evidence from a lender cutoff rule. Working Paper.

Calomiris, C., and J. Mason. 1999. High loan-to-value mortgage lending: Problem or cure. The AEI Press.

Capone, C. A. 2002. Research into mortgage default and affordable housing: A primer. In LISC Center for Home Ownership Summit 2001. Congressional Budget Office. 
Case, K. E., and R. J. Shiller. 2003. Is there a bubble in the housing market? Brookings Papers on Economic Activity 299342.

Case, K. E., R. J. Shiller, and A. K. Thompson. 2012. What have they been thinking? homebuyer behavior in hot and cold markets. Brookings Papers on Economic Activity 714746.

Da, Z., X. Huang, and L. Jin. 2019. Extrapolative beliefs in the cross-section: What can we learn from the crowds? Working Paper .

Dobbie, W., P. Goldsmith-Pinkham, N. Mahoney, and J. Song. 2017. Bad credit, no problem? credit and labor market consequences of bad credit reports. Working Paper .

Dunn, E., and M. Grabchuk. 2010. Background checks and social effects: Contemporary residential tenant-screening problems in washington state. Seattle Journal for Social Justice 9:319-99.

Freddie Mac. 2001. Single-family seller/servicer guide. In Using FICO Scores in Underwriting, chap. 37.

Garmaise, M. 2015. Borrower misreporting and loan performance. Journal of Finance 70:449-84.

Greenwood, R., and A. Shleifer. 2019. Expectations of returns and expected returns. Review of Financial Studies 714746.

Hanft, G. 2011. Giving arbitration some credit: The enforceability of arbitration clauses under the credit repair organizations act. Fordham Law Review 79.

Herkenhoff, K., G. Phillips, and E. Cohen-Cole. 2017. The impact of consumer credit access on employment, earnings and entrepreneurship. Working Paper .

Koijen, R., M. Schmeling, and E. B. Vrugt. 2015. Survey expectations of returns and asset pricing puzzles. Working Paper .

Kuchler, T., and B. Zafar. 2019. Personal experiences and expectations about aggregate outcomes. Journal of Finance 5:2491-542. 
Lee, D., and W. van der Klaauw. 2010. An introduction to the frbny consumer credit panel. FRBNY staff Reports .

Liberti, J. M., and A. R. Mian. 2009. Estimating the effect of hierarchies on information use. Review of Financial Studies 22:4057-90.

Loesch, M. 1996. A new look at subprime mortgages. Fitch Resarch.

Mian, A. R., and A. Sufi. 2009. The consequences of mortgage credit expansion: Evidence from the u.s. mortgage default crisis. Quarterly Journal of Economics 124:1449-96.

Mian, A. R., and A. Sufi. 2011. House prices, home equity based borrowing, and the u.s. household leverage crisis. American Economic Review 101.

Rajan, U., A. Seru, and V. Vig. 2015. The failure of models that predict failure: Distance, incentives, and defaults. Journal of Financial Economics 115:237-60.

Stein, J. C. 2002. Information production and capital allocation: Decentralized versus hierarchical firm. Journal of Finance 57:1891-921. 


\section{Figure 1}

Credit score around home purchases: homebuyers vs non-homebuyers

This figure shows the average percentage change in credit score of buyers in the four quarters before and after home purchase compared to non-buyers. The credit scores reported here are Equifax risk scores. The sample is from the $5 \%$ random sample and restricted to buyers whose credit score were in the subprime group (550-619) four quarters before home purchase and non-buyers who are matched with buyers on three dimensions: (1) their credit scores at 4 quarters before home purchases, (2) ages and (3) states. Observations in the time periods 2000Q1-2003Q4, 2004Q1-2007Q4, and 2008Q1-2011Q4 are reported separately.

\section{Lagged Subprime Bin (550-619)}
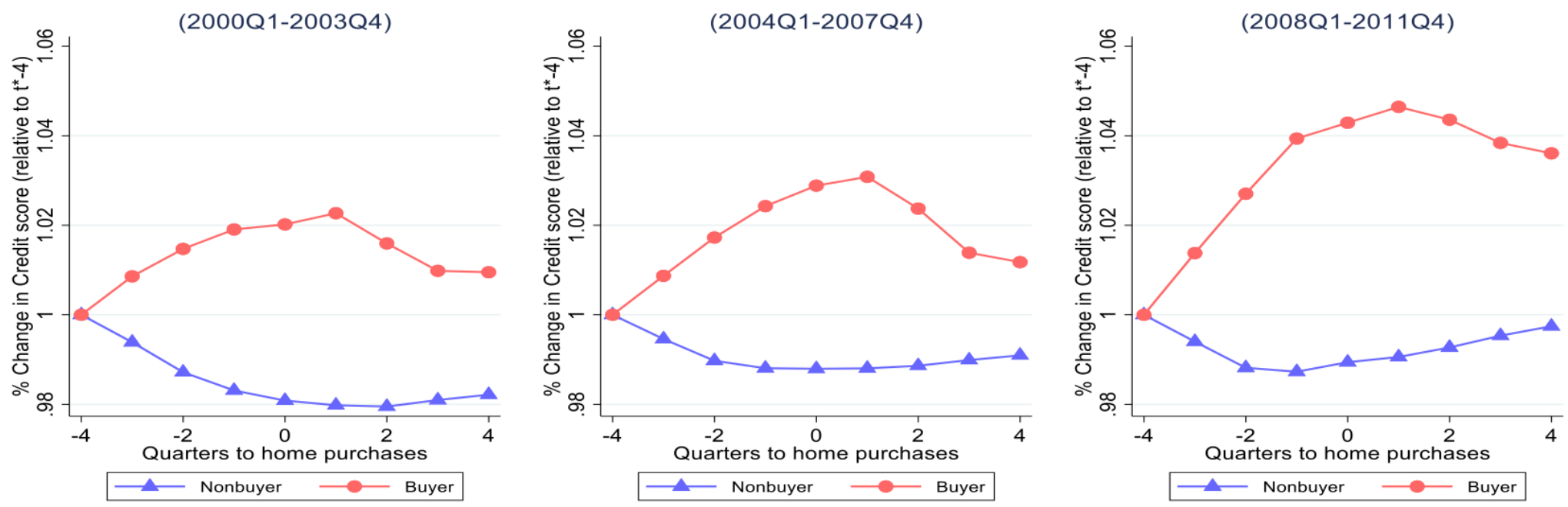


\section{Figure 2}

\section{Credit score after home purchases: crossover vs non-crossover}

This figure shows the average percentage change in credit score of crossover buyers compared to non-crossover buyers in the four quarters after their home purchases. The credit scores reported here are Equifax risk scores. The sample is from the $5 \%$ random sample and restricted to buyers whose credit score at the time of home purchase is in the "near-prime" bin (620-679). Homebuyers are considered crossover if their credit score four quarters before home purchase falls into a lower credit score bin than their credit score bins in the quarter of home purchase. Observations in the time periods 2000Q1-2003Q4, 2004Q1-2007Q4, and 2008Q1-2011Q4 are reported separately.

\section{Current Near-Prime Bin (620-679)}
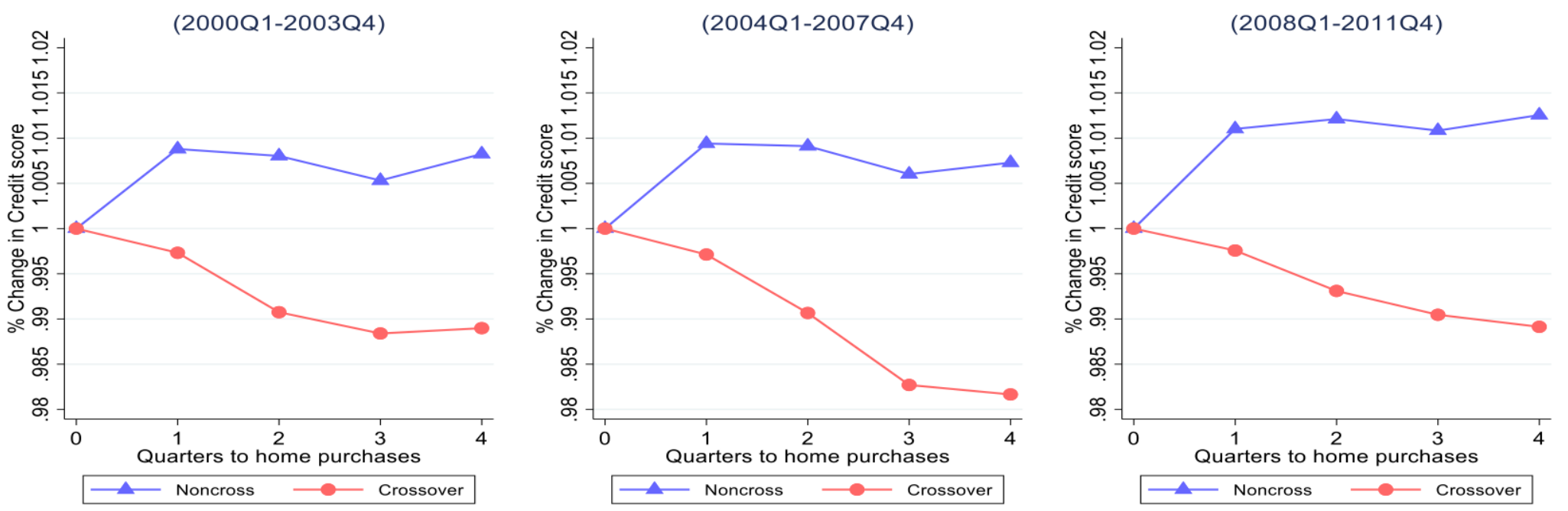


\section{Table 1}

\section{Summary statistics}

In this table, Panel A shows the summary statistics of four-quarter credit score change for all household-quarter level observations and for homebuyers before the quarter of home purchases respectively. The credit scores reported here are Equifax risk scores. Panel B shows the summary statistics of the credit behavior characteristics for all homebuyers at the quarter $\tau^{*}$ of home purchases. "Change in the number of credit cards $\geq 75 \%$ credit limit" is the difference in the average number of open bankcard accounts with balance $\geq 75 \%$ credit limit between period $\left[\tau^{*}-4, \tau^{*}-1\right]$ and period $\left[\tau^{*}-8, \tau^{*}-5\right]$. "Change in credit card balances" is the difference in the average total bankcard balance between period $\left[\tau^{*}-4, \tau^{*}-1\right]$ and period $\left[\tau^{*}-8, \tau^{*}-5\right]$. "Number of newly taken loans" is the total number of positive change in consumer finance trades between each consecutive quarter during the four quarters before home purchases. "Number of newly paid-off loans" is the total number of negative change in consumer finance trades between each consecutive quarter during the four quarters before home purchases. Panel C reports the cumulative delinquency rate by credit score bin at different horizons after the quarter of home purchases. Homebuyers are defined to be delinquent in a given period if there is at least one trade in the categories auto finance, auto bank loans, bank cards, consumer finance, first mortgage, home equity installment or revolving trades, student loans, or other trades considered 90 days past due, 120 days past due, in collections, severely derogatory, or bankrupt.

\begin{tabular}{|c|c|c|c|c|c|}
\hline Variable & mean & sd & $\mathrm{p} 25$ & $\mathrm{p} 50$ & p75 \\
\hline \multicolumn{6}{|l|}{ Panel A: credit score change } \\
\hline \multicolumn{6}{|c|}{ Household-quarter observations until quarter $\tau *$ of home purchases $(N=6175905)$} \\
\hline Crossover $($ riskscore bin $(t)>$ riskscore bin $(t-4))$ & 0.23 & 0.42 & 0.00 & 0.00 & 0.00 \\
\hline$\Delta$ Riskscore $(t-4$ to $t)$ & 6.76 & 44.58 & -12.00 & 7.00 & 28.00 \\
\hline \multicolumn{6}{|c|}{ Household-quarter observations at quarter $\tau^{*}$ of home purchases $(N=170624)$} \\
\hline Crossover (riskscore bin $\left(\tau^{*}\right)>$ riskscore bin $\left(\tau^{*}-4\right)$ ) & 0.29 & 0.45 & 0.00 & 0.00 & 1.00 \\
\hline$\Delta$ Riskscore $\left(\tau^{*}-4\right.$ to $\left.\tau^{*}\right)$ & 9.99 & 45.27 & -14.00 & 11.00 & 36.00 \\
\hline \multicolumn{6}{|c|}{ Panel B: credit behavior (household-quarter observations at quarter $\tau^{*}$ of home purchases; $N=170624$ ) } \\
\hline Change in the number of credit cards with balance $\geq 75 \%$ credit limit & 0.02 & 0.75 & -0.25 & 0.00 & 0.25 \\
\hline Change in credit card balances & 819.60 & 5486.75 & -303.00 & 225.50 & 1481.50 \\
\hline Number of newly taken loans & 0.33 & 0.77 & 0.00 & 0.00 & 0.00 \\
\hline Number of newly paid-off loans & 0.20 & 0.62 & 0.00 & 0.00 & 0.00 \\
\hline
\end{tabular}

Panel C: cumulative delinquency by credit score bin (household-quarter observations at quarter $\tau^{*}$ of home purchases; $N=170624$ )

\begin{tabular}{|c|c|c|c|c|}
\hline & {$\left[\tau^{*}+1, \tau^{*}+4\right]$} & {$\left[\tau^{*}+1, \tau^{*}+8\right]$} & {$\left[\tau^{*}+1, \tau^{*}+12\right]$} & $\overline{\left[\tau^{*}+1, \tau^{*}+16\right.}$ \\
\hline Subprime [550-619] & $26.02 \%$ & $38.00 \%$ & $45.62 \%$ & $50.55 \%$ \\
\hline Near prime [620-679] & $8.63 \%$ & $16.22 \%$ & $22.27 \%$ & $26.82 \%$ \\
\hline Prime $[680-739]$ & $2.27 \%$ & $5.53 \%$ & $8.94 \%$ & $11.86 \%$ \\
\hline
\end{tabular}




\section{Table 2}

\section{Hazard rate of home purchase after crossing over to a higher credit score bin}

This table estimates the hazard rate of home purchases (the probability of home purchase in quarter $t$ given not previously owning a house) using a probit binary choice model. The results are reported as the marginal effects of independent variables. The sample is based on the $5 \%$ random sample of the primary-individual data from FRBNY Consumer Credit Panel/Equifax Data. The panel covers from 2000 to 2011. Individuals exit the sample after the quarter of their home purchases. The main variable, "Crossover", is a dummy variable which equals one if the credit score bin at quarter $t-4$ is lower than the credit score bin at quarter $t$. All specifications control for credit score of quarter $t$ and its quadratic form. The credit scores reported here are Equifax risk scores. Column (1) contains no fixed effects. Column (2) includes age, state and home purchase year fixed effects. Column (3) uses age and state times year fixed effects. Columns (4)-(6) report the results for time periods 2000Q1-2003Q4, 2004Q1-2007Q4, and 2008Q1-2011Q4 separately. ${ }^{*} 10 \%,{ }^{* *} 5 \%,{ }^{* * *} 1 \%$ significance.

\begin{tabular}{|c|c|c|c|c|c|c|}
\hline & (1) & $(2)$ & $(3)$ & $(4)$ & $(5)$ & (6) \\
\hline Dependent variable: & \multicolumn{6}{|c|}{ Home purchase in qtr $t$ given not previously owning a house } \\
\hline Sample: & All years & All years & All years & $\begin{array}{l}\text { 2000Q1- } \\
2003 Q 4\end{array}$ & $\begin{array}{l}\text { 2004Q1- } \\
\text { 2007Q4 }\end{array}$ & $\begin{array}{c}\text { 2008Q1- } \\
\text { 2011Q4 }\end{array}$ \\
\hline Crossover & $\begin{array}{c}0.0238^{* * *} \\
(0.00212)\end{array}$ & $\begin{array}{c}0.0219^{* * *} \\
(0.00215)\end{array}$ & $\begin{array}{c}0.0219^{* * * *} \\
(0.00215)\end{array}$ & $\begin{array}{c}0.0106^{* * *} \\
(0.00129)\end{array}$ & $\begin{array}{c}0.0366^{* * *} \\
(0.00346)\end{array}$ & $\begin{array}{l}0.0404^{* * *} \\
(0.00396)\end{array}$ \\
\hline Credit score $(t)$ and quadratic form & Yes & Yes & Yes & Yes & Yes & Yes \\
\hline Age FE & No & Yes & Yes & Yes & Yes & Yes \\
\hline Year FE & No & Yes & No & No & No & No \\
\hline State FE & No & Yes & No & No & No & No \\
\hline State $\times$ year $\mathrm{FE}$ & No & No & Yes & Yes & Yes & Yes \\
\hline Observations & $6,141,555$ & $6,141,555$ & $6,141,555$ & $3,428,790$ & $2,031,671$ & 681,058 \\
\hline Pseudo-R2 & 0.0051 & 0.0241 & 0.0252 & 0.0154 & 0.0151 & 0.0146 \\
\hline
\end{tabular}




\section{Table 3}

The heterogenous effects of the change in credit score on the hazard rate of home purchases: crossover vs. non-crossover

This table estimates the hazard rate of home purchases (the probability of home purchase in quarter $t$ given not previously owning a house) using a probit binary choice model. The results are reported as the marginal effects of independent variables. The sample is based on the $5 \%$ random sample of the primary-individual data from FRBNY Consumer Credit Panel/Equifax Data. The panel covers from 2000 to 2011. Individuals exit the sample after the quarter of their home purchases. "Crossover" is one if the credit score bin at quarter $t-4$ is lower than the credit score bin at quarter $t$. " $\Delta$ Riskscore $(\tau-4$ to $\tau$, in $100 \mathrm{~s})$ " is the change in credit score from quarter $t-4$ to $t$. All specifications control for credit score of quarter $t$ and its quadratic form. The credit scores reported here are Equifax risk scores. Column (1) contains no fixed effects. Column (2) includes age, state and home purchase year fixed effects. Column (3) uses age and state times year fixed effects. Standard errors displayed in parentheses below the coefficient estimates are robust to heteroskedascity and clustered at the state level. ${ }^{*} 10 \%,{ }^{* *} 5 \%,{ }^{* * *} 1 \%$ significance.

\begin{tabular}{lccc}
\hline & $(1)$ & $(2)$ & $(3)$ \\
\hline Dependent variable: & Home purchase in $q$ qtr $t$ given not previously owning a house \\
\hline Crossover & -0.0001781 & 0.0002888 & 0.0003444 \\
& $(.0003875)$ & $(.0003955)$ & $(.0003927)$ \\
$\Delta$ Riskscore $(t-4$ to $t$, in 100s) & 0.00220 & -0.00165 & -0.00160 \\
& $(0.00201)$ & $(0.00220)$ & $(0.00219)$ \\
Crossover $\times \Delta$ Riskscore $(t-4$ to $t$, in $100 \mathrm{~s})$ & $0.0381^{* * *}$ & $0.0399^{* * *}$ & $0.0397^{* * *}$ \\
& $(0.00179)$ & $(0.00146)$ & $(0.00145)$ \\
\hline Credit score $(t)$ and quadratic form & Yes & Yes & Yes \\
Age FE & No & Yes & Yes \\
Year FE & No & Yes & No \\
State FE & No & No & No \\
State $\times$ Year FE & No & $6,141,555$ & $6,141,555$ \\
\hline Observations & $6,141,555$ & 0.0254 & 0.0265 \\
Pseudo-R2 & 0.0066 & & \\
\hline
\end{tabular}


Table 4

Delinquency rate after home purchases: Crossover vs Non-crossover

This table reports the cumulative delinquency rate at different horizons after the quarter of home purchases $\left(\tau^{*}\right)$ by credit score bin at time of home purchase and crossover status. The sample includes homebuyers in the $5 \%$ random sample of the primary-individual data from FRBNY Consumer Credit Panel/Equifax Data. The crossover group includes individuals whose credit score bin at quarter $t-4$ is lower than the credit score bin at quarter $t$. The credit scores reported here are Equifax risk scores. The differences between the crossover group and the non-crossover group and the corresponding t-statistics are also reported for each of credit score bin and time periods. Results are reported separately for subprime, near-prime and prime groups defined by individuals' credit scores at the time of home purchases. An individual is defined to be delinquent in a given period if there is at least one trade considered 90 days past due, 120 days past due, in collections, severely derogatory, or bankrupt. ${ }^{*} 10 \%,{ }^{* *} 5 \%,{ }^{* * *} 1 \%$ significance.

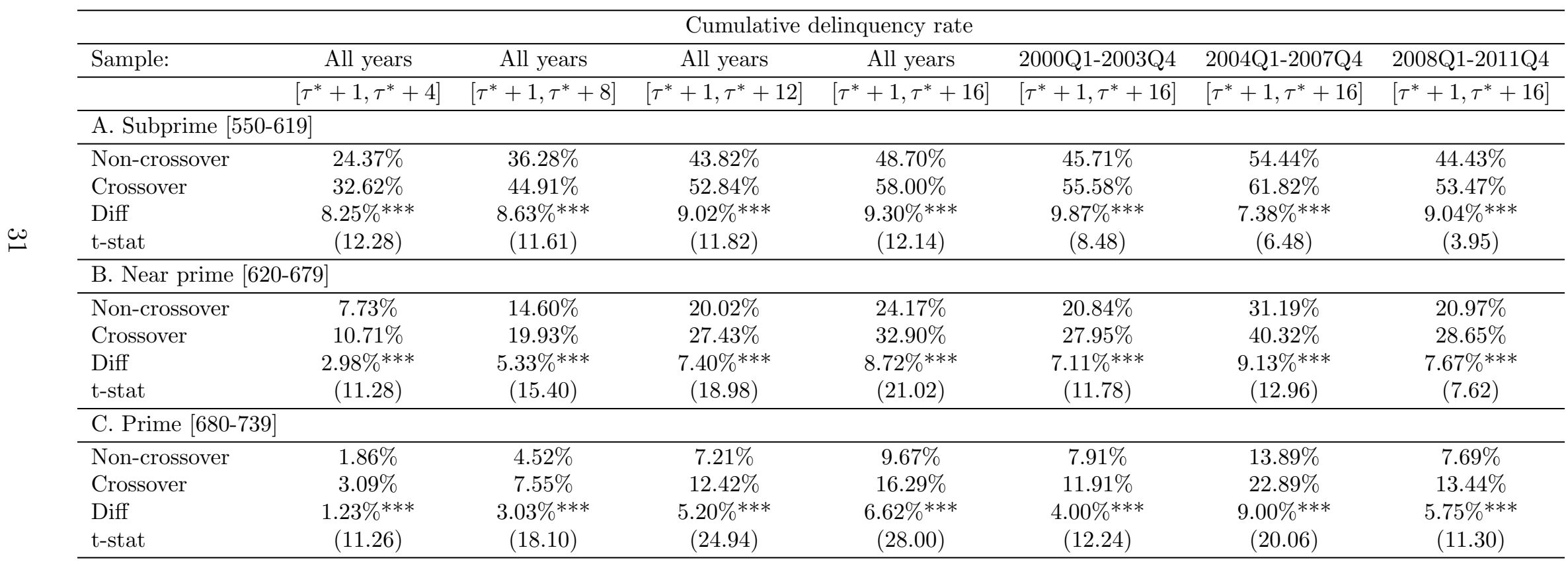




\section{Table 5}

\section{Multivariate analysis: predicting delinquency rate after home purchases}

The table reports the estimates from the linear probability model for the post-purchase delinquency rate. The sample includes homebuyers in the $5 \%$ random sample of the primary-individual data from FRBNY Consumer Credit Panel/Equifax Data. The dependent variable is a dummy that takes on the value of one if there is at least one delinquent trade in the two year period after home purchase. An individual is defined to be delinquent in a given period if there is at least one trade considered 90 days past due, 120 days past due, in collections, severely derogatory, or bankrupt. Crossover is one if the credit score bin at quarter $\tau^{*}-4$ is lower than the credit score bin at $\tau^{*}$. All specifications control for credit score of quarter $\tau^{*}$ and its quadratic form. The credit scores reported here are Equifax risk scores. Column (1) contains no fixed effects. Column (2) includes age, state and home purchase year fixed effects. Column (3) uses age and state times home purchase year fixed effects. Columns (4)-(6) report the results for time periods 2000Q1-2003Q4, 2004Q1-2007Q4, and 2008Q1-2011Q4 separately. Standard errors displayed in parentheses below the coefficient estimates are robust to heteroskedascity and clustered at the state level. ${ }^{*} 10 \%,{ }^{* *} 5 \%,{ }^{* * *} 1 \%$ significance.

\begin{tabular}{|c|c|c|c|c|c|c|}
\hline & (1) & $(2)$ & $(3)$ & $(4)$ & $(5)$ & $(6)$ \\
\hline Dependent variable: & \multicolumn{6}{|c|}{ Post-purchase 2-year cumulative delinquency rate } \\
\hline Credit score $\left(\tau^{*}\right)$ and quadratic form & Yes & Yes & Yes & Yes & Yes & Yes \\
\hline Age FE & No & Yes & Yes & Yes & Yes & Yes \\
\hline State $\times$ home purchase year FE & No & No & Yes & Yes & Yes & Yes \\
\hline Observations & 170,624 & 170,624 & 170,624 & 75,669 & 63,894 & 27,279 \\
\hline R-squared & 0.191 & 0.204 & 0.209 & 0.215 & 0.203 & 0.184 \\
\hline
\end{tabular}




\section{Table 6}

The heterogenous effects of the change in credit score: crossover vs. noncrossover

The table reports the estimates from the linear probability model related to the heterogenous effects of change in credit score on post-home purchase delinquency between individuals who crossover and do not crossover to a higher credit score bin before home purchases. The sample includes homebuyers in the $5 \%$ random sample of the primary-individual data from FRBNY Consumer Credit Panel/Equifax Data. The dependent variable is a dummy that takes on the value of one if there is at least one delinquent trade in the two year period after home purchase. Crossover is one if the credit score bin at quarter $\tau^{*}-4$ is lower than the credit score bin at $\tau^{*}$. $\Delta$ Riskscore $\left(\tau^{*}-4\right.$ to $\tau^{*}$, in 100s) is the (de-meaned) change in credit score from quarter $\tau^{*}-4$ to $\tau^{*}$. All specifications control for credit score of quarter $\tau^{*}$ and its quadratic form. The credit scores reported here are Equifax risk scores. Column (1) contains no fixed effects. Column (2) includes age, state and home purchase year fixed effects. Column (3) uses age and state times home purchase year fixed effects. Standard errors displayed in parentheses below the coefficient estimates are robust to heteroskedascity and clustered at the state level. ${ }^{*} 10 \%,{ }^{* *} 5 \%,{ }^{* * *} 1 \%$ significance.

\begin{tabular}{lccc}
\hline & $(1)$ & $(2)$ & $(3)$ \\
\hline Dependent variable: & Post-Purchase 2 -Year & Cumulative Delinquency Rate \\
\hline Crossover & -0.00315 & -0.00285 & -0.00299 \\
& $(0.00294)$ & $(0.00282)$ & $(0.00287)$ \\
$\Delta$ Riskscore $\left(\tau^{*}-4\right.$ to $\tau^{*}$, in $\left.100 \mathrm{~s}\right)$ & $0.00854^{* *}$ & $0.00893^{* * *}$ & $0.00893^{* * *}$ \\
& $(0.00339)$ & $(0.00305)$ & $(0.00316)$ \\
Crossover $\times \Delta$ Riskscore $\left(\tau^{*}-4\right.$ to $\tau^{*}$, in $\left.100 \mathrm{~s}\right)$ & $0.0410^{* * *}$ & $0.0317^{* * *}$ & $0.0304^{* * *}$ \\
& $(0.00675)$ & $(0.00667)$ & $(0.00674)$ \\
\hline Credit score $\left(\tau^{*}\right)$ and quadratic form & Yes & Yes & Yes \\
Age FE & No & Yes & Yes \\
State FE & No & Yes & No \\
Home purchase year FE & No & Yes & No \\
State $\times$ home purchase year FE & No & No & Yes \\
\hline Observations & 170,624 & 170,624 & 170,624 \\
R-squared & 0.192 & 0.204 & 0.210 \\
\hline
\end{tabular}




\section{Table 7}

Robustness test: predicting delinquency rate after home purchases (with loan-to-value controls)

The table reports the estimates from the linear probability model for the post-purchase delinquency rate. This table uses a merged sample of home buyers between the FRBNY Consumer Credit Panel/Equifax Data and the Loan Performance and Lender Processing Services (LPS) data (source: Equifax Credit Risks Insight Servicing and Black Knight McDash Data). The dependent variable is a dummy that takes on the value of one if there is at least one delinquent trade in the two year period after home purchase. An individual is defined to be delinquent in a given period if there is at least one trade considered 90 days past due, 120 days past due, in collections, severely derogatory, or bankrupt. Crossover is one if the credit score bin at quarter $\tau^{*}-4$ is lower than the credit score bin at $\tau^{*}$. "Loan-to-value" ratio is defined as the ratio between the origination amount and the appraisal amount. All specifications control for credit score of quarter $\tau^{*}$ and its quadratic form. Column (1) contains no fixed effects. Column (2) includes age, state and home purchase year fixed effects. Column (3) uses age and state times home purchase year fixed effects. Standard errors displayed in parentheses below the coefficient estimates are robust to heteroskedascity and clustered at the state level. ${ }^{*} 10 \%,{ }^{* *} 5 \%,{ }^{* * *} 1 \%$ significance.

\begin{tabular}{lccc}
\hline & $(1)$ & $(2)$ & $(3)$ \\
\hline Dependent variable: & \multicolumn{1}{c}{ Post-purchase 2 -year cumulative delinquency rate } \\
\hline Crossover & $0.0142^{* * *}$ & $0.0112^{* * *}$ & $0.0108^{* * *}$ \\
& $(0.00353)$ & $(0.00364)$ & $(0.00356)$ \\
Loan-to-value & $0.0371^{* * *}$ & $0.0639^{* * *}$ & $0.0622^{* * *}$ \\
& $(0.0124)$ & $(0.0127)$ & $(0.0132)$ \\
\hline Credit score $\left(\tau^{*}\right)$ and quadratic form & Yes & Yes & Yes \\
Age FE & No & Yes & Yes \\
State FE & No & Yes & No \\
Home purchase Year FE & No & Yes & No \\
State x Home purchase year FE & No & No & Yes \\
\hline Observations & 31,089 & 31,089 & 31,089 \\
R-squared & 0.143 & 0.162 & 0.178 \\
\hline
\end{tabular}




\section{Table 8}

Multivariate analysis: predicting mortgage delinquency rate after home purchases

The table reports the estimates from the linear probability model for the post-purchase delinquency rate. The sample includes homebuyers in the $5 \%$ random sample of the primary-individual data from FRBNY Consumer Credit Panel/Equifax Data. The dependent variable is a dummy that takes on the value of one if the mortgage account becomes delinquent in the two year period after home purchase. Crossover is one if the credit score bin at quarter $\tau^{*}-4$ is lower than the credit score bin at $\tau^{*}$. All specifications control for credit score of quarter $\tau^{*}$ and its quadratic form. The credit scores reported here are Equifax risk scores. Column (1) contains no fixed effects. Column (2) includes age, state and home purchase year fixed effects. Column (3) uses age and state times home purchase year fixed effects. Standard errors displayed in parentheses below the coefficient estimates are robust to heteroskedascity and clustered at the state level. ${ }^{*} 10 \%,{ }^{* *} 5 \%,{ }^{* * *} 1 \%$ significance.

\begin{tabular}{lccc}
\hline & $(1)$ & $(2)$ & $(3)$ \\
\hline Dependent variable: & Post-purchase & 2-year cumulative & mortgage \\
& $0.00940^{* * *}$ & $0.00568^{* * *}$ & $0.00492^{* * *}$ \\
\hline Crossover & $(0.00177)$ & $(0.000932)$ & $(0.000863)$ \\
\hline Credit score $\left(\tau^{*}\right)$ and quadratic form & Yes & Yes & Yes \\
Age FE & No & Yes & Yes \\
State FE & No & Yes & No \\
Home purchase Year FE & No & Yes & No \\
State x Home purchase year FE & No & No & Yes \\
\hline Observations & 170,624 & 170,624 & 170,624 \\
R-squared & 0.017 & 0.043 & 0.060 \\
\hline
\end{tabular}




\section{Table 9}

\section{Incentive and probability of credit behavior}

This table reports the probability of credit behavior by three-year average housing price change quartiles. The sample includes homebuyers in the the $5 \%$ random sample of the primary-individual data from FRBNY Consumer Credit Panel/Equifax Data. "Number of newly taken loans $>0$ " indicates that there is at least one increase in consumer finance trades between any two consecutive quarters from $\tau^{*}-4$ to $\tau^{*}-1$. "Number of paid-off loans $>0$ " indicates that there is at least one decrease in consumer finance trades in any two consecutive quarters from $\tau^{*}-4$ to $\tau^{*}-1$. "Reduce utilization by reducing balance" indicates that there is both a negative change in the number of credit cards $\geq 75 \%$ credit limit and a decrease in total credit card balance $\left[\tau^{*}-8, \tau^{*}-5\right]$ to $\left[\tau^{*}-4, \tau^{*}-1\right]$. "Reduce utilization by increasing limit" indicates that there is a decrease in the number of credit cards $\geq 75 \%$ credit limit and an increase in total credit card high credit from $\left[\tau^{*}-8, \tau^{*}-5\right]$ to $\left[\tau^{*}-4, \tau^{*}-1\right]$. The probability of each credit behavior is reported separately for each quartile of 3-year average housing price change. The 3-year average housing price change is constructed by taking the average of the yearly growth rate of Corelogic House Price Index at the CBSA level for each year and two years prior. ${ }^{*} 10 \%,{ }^{* *} 5 \%,{ }^{* * *} 1 \%$ significance.

\begin{tabular}{|c|c|c|c|c|}
\hline & (1) & $(2)$ & $(3)$ & $(4)$ \\
\hline Q1 (Bottom growth in housing price) & $3.86 \%$ & $13.01 \%$ & $12.70 \%$ & $17.72 \%$ \\
\hline Q4 (Top growth in housing price) & $7.03 \%$ & $6.83 \%$ & $9.82 \%$ & $23.96 \%$ \\
\hline Diff (Top-Bottom) & $\begin{array}{c}3.17 \% * * * \\
(16.71)\end{array}$ & $\begin{array}{c}-6.18 \% * * * \\
(-28.93)\end{array}$ & $\begin{array}{c}-2.88 \% * * * \\
(-12.04)\end{array}$ & $\begin{array}{c}6.25 \% * * * \\
(1916)\end{array}$ \\
\hline
\end{tabular}




\section{Table 10}

Incentive and home purchases: hazard rate of home purchase after crossing over This table estimates the hazard rate of home purchases (the probability of home purchase in quarter $t$ given not previously owning a house) using a probit binary choice model. The results are reported as the marginal effects of independent variables. The sample is based on the $5 \%$ random sample of the primary-individual data from FRBNY Consumer Credit Panel/Equifax Data. The panel covers from 2000 to 2011. Individuals exit the sample after the quarter of their home purchases. The sample includes only those whose residence is in a CBSA with the lowest or highest 3-year average housing price growth quartile. "Crossover" is one if the credit score bin at quarter $t-4$ is lower than the credit score bin at quarter $t$. The credit scores reported here are Equifax risk scores. "Top HPI growth quartile" is a dummy that takes on the value of one if the CBSA residence of the homebuyer is in the fourth quartile of the 3-year average housing price growth quartile. All specifications control for credit score of quarter $t$ and its quadratic form. Column (1) contains no fixed effects. Column (2) includes age, state and home purchase year fixed effects. Column (3) uses age and state times home purchase year fixed effects. Standard errors displayed in parentheses below the coefficient estimates are robust to heteroskedascity and clustered at the state level. ${ }^{*} 10 \%,{ }^{* *} 5 \%,{ }^{* * *} 1 \%$ significance.

\begin{tabular}{lccc}
\hline & $(1)$ & $(2)$ & $(3)$ \\
\hline Dependent variable & Home purchase & in quarter & $t$ given not previously owning a house \\
\hline Crossover & $0.0220^{* * *}$ & $0.0200^{* * *}$ & $0.0201^{* * *}$ \\
& $(0.00170)$ & $(0.00168)$ & $(0.00169)$ \\
Top HPI Quartile & $-0.00771^{* * *}$ & $0.00257^{* * *}$ & $0.00202^{* *}$ \\
& $(0.00258)$ & $(0.000992)$ & $(0.000892)$ \\
Crossover $\times$ Top HPI Quartile & $0.00416^{* * *}$ & $0.00404^{* * *}$ & $0.00383^{* * *}$ \\
& $(0.00116)$ & $(0.00115)$ & $(0.00114)$ \\
\hline Credit score $(t)$ and quadratic form & Yes & Yes & Yes \\
Age FE & No & Yes & Yes \\
Year FE & No & Yes & No \\
State FE & No & Yes & Yes \\
State $\times$ year FE & No & No & $5,572,593$ \\
\hline Observations & $5,572,593$ & $5,572,593$ & 0.0258 \\
Pseudo-R2 & 0.0057 & 0.0246 & \\
\hline
\end{tabular}




\section{Table 11}

\section{Incentive and strategic behaviors: delinquency after home purchases}

The table reports the estimates from the linear probability model related to the heterogenous effects of change in credit score on post-home purchase delinquency between individuals who crossover and do not crossover to a higher credit score bin before home purchases. The sample includes homebuyers in the 5\% random sample of the primary-individual data from FRBNY Consumer Credit Panel/Equifax Data. The sample includes only those whose residence is in a CBSA with the lowest or highest 3-year average housing price growth quartile. The dependent variable is a dummy that takes on the value of one if there is at least one delinquent trade in the two year period after home purchase. "Crossover" is one if the credit score bin at quarter $\tau^{*}-4$ is lower than the credit score bin at $\tau^{*}$. The credit scores reported here are Equifax risk scores. "Top HPI growth quartile" is a dummy that takes on the value of one if the CBSA residence of the homebuyer is in the fourth quartile of the 3-year average housing price growth quartile. All specifications control for credit score of quarter $\tau^{*}$ and its quadratic form. Column (1) contains no fixed effects. Column (2) includes age, state and home purchase year fixed effects. Column (3) uses age and state times home purchase year fixed effects. Standard errors displayed in parentheses below the coefficient estimates are robust to heteroskedascity and clustered at the state level. ${ }^{*} 10 \%,{ }^{* *} 5 \%,{ }^{* * *} 1 \%$ significance.

\begin{tabular}{lccc}
\hline & $(1)$ & $(2)$ & $(3)$ \\
\hline Dependent variable & Post-purchase 2-year cumulative delinquency rate \\
\hline Crossover & $0.0145^{* * *}$ & $0.0105^{* *}$ & $0.0105^{* *}$ \\
& $(0.00456)$ & $(0.00424)$ & $(0.00436)$ \\
Top HPI Growth Quartile & $0.0101^{* * *}$ & -0.00217 & -0.00289 \\
& $(0.00301)$ & $(0.00430)$ & $(0.00440)$ \\
Crossover $\times$ Top HPI Growth Quartile & $0.00923^{*}$ & $0.00972^{* *}$ & $0.00845^{*}$ \\
& $(0.00472)$ & $(0.00448)$ & $(0.00451)$ \\
\hline Credit score $\left(\tau^{*}\right)$ and quadratic form & Yes & Yes & Yes \\
Age FE & No & Yes & Yes \\
State FE & No & Yes & No \\
Home purchase year FE & No & Yes & Yes \\
State $\times$ home purchase year FE & No & No & 105,630 \\
\hline Observations & 105,630 & 105,630 & 0.206 \\
R-squared & 0.184 & 0.198 & \\
\hline
\end{tabular}




\section{Appendix}

\section{A.1 Credit Behaviors that Predict Increases in Credit Scores}

In order to check if individuals engage in building up their credit scores, we identify a set of credit behaviors that predict the increase in credit scores in the short term. A main factor that affects credit scores is the overall amount of money an individual owes (including how close the individual is to the limits on her credit cards). ${ }^{15}$ We focus on two potential ways individuals could make improvements on this factor: (1) reducing credit card utilization rates, specifically, reducing the number of credit cards with utilization rate greater than $75 \%$; $^{16}$ and (2) paying off personal loans.

However, these active behaviors are not necessarily the cosmetic-type strategic behaviors that only increase credit scores but do not improve credit quality. For example, if an individual decides to become more prudent about her finances - for example, reducing credit card utilization rates by reducing balances rather than by increasing limits, or paying off loans without taking out new ones, then their credit quality may actually improve along with an increase in their credit scores. Therefore, we further separate the two active behaviors into the prudent type and the strategic type of behaviors; the former includes reducing credit card utilization rates by reducing balances and paying off loans without taking out ones, while the latter includes reducing credit card utilization rates by other methods (including increasing limits) and paying off loans but also taking out new ones.

The dependent variable is an indicator variable which equals one if the individual's score increases during the four quarters before the home purchase. The results are reported in Table A.5. We control for age, state, and year effect to isolate the effect of active credit behaviors from the improve of credit scores with age, with possible heterogeneous income increase across states and years. Also, considering the increase of credit scores may vary with different credit scores, we control for past credit score bin in Col (1), and a quadratic form of credit score in Col (2). Both columns show that all these four behaviors could boost credit

\footnotetext{
${ }^{15}$ See, for example, the Wall Street Journal article "How to Perfect Your Credit Score".

${ }^{16}$ As discussed before, we prefer this measure to the aggregate utilization rate (defined as total balance divided by total limit) because the latter may not capture strategic allocations across cards. Detailed information about individual card utilization rate is not available in the dataset.
} 
scores - it is more likely for an individual to increase her credit scores if she has paid off personal loans or reduced the number of credit cards with high utilization rates, no matter the behavior is the prudent type or the strategic type. 


\section{Table A.1}

Interest rates and credit score bins

This table uses a merged sample of home buyers between the FRBNY Consumer Credit Panel/Equifax Data and the Loan Performance and Lender Processing Services (LPS) data (source: Equifax Credit Risks Insight Servicing and Black Knight McDash Data). Panel A reports the summary statistics of interest rates obtained by home buyers by credit score bins. The credit scores reported here are Equifax risk scores. Panel B reports the regression results controlling for loan-to-value ratio, age effects and state-year effects.

A.Summary statistics of interest rate (in percentage)

\begin{tabular}{lccc}
\hline & Obs & Mean & sd \\
\hline Subprime & 8568 & 6.366 & 1.312 \\
Near prime & 20796 & 6.006 & 1.143 \\
Prime & 34405 & 5.804 & 1.027 \\
\hline
\end{tabular}

B. Regression

\begin{tabular}{lc}
\hline Dependent variable: & Interest rate \\
\hline Near Prime & $-0.248^{* * *}$ \\
& $(0.0141)$ \\
Prime & $-0.410^{* * *}$ \\
& $(0.0145)$ \\
Loan-to value & $0.345^{* * *}$ \\
& $(0.0490)$ \\
Constant & $6.331^{* * *}$ \\
& $(0.0529)$ \\
\hline Age FE & Yes \\
State x home purchase year FE & Yes \\
\hline Observations & 60,667 \\
R-squared & 0.360 \\
\hline
\end{tabular}




\section{Table A.2}

Loan-to-value ratio: crossover vs. non-crossover

This table shows how the loan-to-value ratio differs between the crossover and non-crossover group. The data is from a merged sample between the FRBNY Consumer Credit Panel/Equifax Data and the Loan Performance and Lender Processing Services (LPS) data (source: Equifax Credit Risks Insight Servicing and Black Knight McDash Data). The sample includes all homebuyers who purchase their houses at quarter $\tau^{*}$. The dependent variable is the "loan-to-value" ratio which is defined as the ratio between the origination amount and the appraisal amount of the home purchase. "Crossover" is one if the credit score bin at quarter $\tau^{*}-4$ is lower than the credit score bin at $\tau^{*}$. All specifications control for credit score of quarter $\tau^{*}$ and its quadratic form. The credit scores reported here are Equifax risk scores. Column (1) contains no fixed effects. Column (2) includes age, state and home purchase year fixed effects. Column (3) uses age and state times home purchase year fixed effects. Standard errors displayed in parentheses below the coefficient estimates are robust to heteroskedascity and clustered at the state level. ${ }^{*} 10 \%,{ }^{* *} 5 \%,{ }^{* * *} 1 \%$ significance.

\begin{tabular}{lccc}
\hline & $(1)$ & $(2)$ & $(3)$ \\
\hline Dependent Variable: & Loan-to-Value & (origination amount/appraisal amount) \\
\hline Crossover & $0.0101^{* * *}$ & $0.00881^{* * *}$ & $0.00825^{* * *}$ \\
& $(0.00213)$ & $(0.00204)$ & $(0.00208)$ \\
\hline Credit score $\left(\tau^{*}\right)$ and quadratic form & Yes & Yes & Yes \\
Age FE & No & Yes & Yes \\
State FE & No & Yes & No \\
Home purchase year FE & No & Yes & No \\
State $\times$ Home purchase year FE & No & No & Yes \\
\hline Observations & 31,089 & 31,089 & 31,089 \\
R-squared & 0.021 & 0.150 & 0.173 \\
\hline
\end{tabular}




\section{Table A.3}

Robustness test: hazard rate of home purchase after crossing over (excluding individuals with bankruptcy flag)

This table estimates the hazard rate of home purchases (the probability of home purchase in quarter $t$ given not previously owning a house) using a probit binary choice model. The results are reported as the marginal effects of independent variables. The sample is based on the $5 \%$ random sample of the primary-individual data from FRBNY Consumer Credit Panel/Equifax Data and excludes the individuals who ever had a bankruptcy flag in our sample period. The panel covers from 2000 to 2011. Individuals exit the sample after the quarter of their home purchases. The main variable "Crossover" is a dummy variable which equals one if the credit score bin at quarter $t-4$ is lower than the credit score bin at quarter $t$. All specifications control for credit score of quarter $t$ and its quadratic form. The credit scores reported here are Equifax risk scores. Column (1) contains no fixed effects. Column (2) includes age, state and home purchase year fixed effects. Column (3) uses age and state times home purchase year fixed effects. ${ }^{*} 10 \%,{ }^{* *} 5 \%,{ }^{* * *} 1 \%$ significance.

\begin{tabular}{lccc}
\hline & $(1)$ & $(2)$ & $(3)$ \\
\hline Dependent variable: & Home purchase in quarter & t given not previously owning a home \\
\hline Crossover & $0.0234^{* * *}$ & $0.0214^{* * *}$ & $0.0214^{* * *}$ \\
& $(0.00204)$ & $(0.00208)$ & $(0.00208)$ \\
\hline Credit score $(t)$ and quadratic form & Yes & Yes & Yes \\
Age FE & No & Yes & Yes \\
Year FE & No & Yes & No \\
State FE & No & Yes & No \\
State $\times$ Year FE & No & No & Yes \\
\hline Observations & $5,761,152$ & $5,761,152$ & $5,761,152$ \\
Pseudo-R2 & 0.0054 & 0.0253 & 0.0265 \\
\hline
\end{tabular}




\section{Table A.4}

Robustness test: predicting delinquency rate after home purchases (excluding individuals with bankruptcy flag)

The table reports the estimates from the linear probability model for the post-purchase delinquency rate. The sample includes homebuyers in the $5 \%$ random sample of the primary-individual data from FRBNY Consumer Credit Panel/Equifax Data and excludes the individuals who ever had a bankruptcy flag in our sample period. The dependent variable is a dummy that takes on the value of one if there is at least one delinquent trade in the two year period after home purchase. An individual is defined to be delinquent in a given period if there is at least one trade considered 90 days past due, 120 days past due, in collections, severely derogatory, or bankrupt. Crossover is one if the credit score bin at quarter $\tau^{*}-4$ is lower than the credit score bin at $\tau^{*}$. All specifications control for credit score of quarter $\tau^{*}$ and its quadratic form. The credit scores reported here are Equifax risk scores. Column (1) contains no fixed effects. Column (2) includes age, state and home purchase year fixed effects. Column (3) uses age and state times year fixed effects. Standard errors displayed in parentheses below the coefficient estimates are robust to heteroskedascity and clustered at the state level. ${ }^{*} 10 \%,{ }^{* *} 5 \%,{ }^{* * *} 1 \%$ significance.

\begin{tabular}{lccc}
\hline & $(1)$ & $(2)$ & $(3)$ \\
\hline Dependent variable: & \multicolumn{1}{c}{ Post-purchase 2 -year } & cumulative delinquency rate \\
\hline Crossover & $0.0226^{* * *}$ & $0.0190^{* * *}$ & $0.0183^{* * *}$ \\
& $(0.00236)$ & $(0.00198)$ & $(0.00197)$ \\
\hline Credit score $\left(\tau^{*}\right)$ and quadratic form & Yes & Yes & Yes \\
Age FE & No & Yes & Yes \\
State FE & No & Yes & No \\
Home purchase year FE & No & Yes & No \\
State x Home purchase year FE & No & No & Yes \\
\hline Observations & 152,213 & 152,213 & 152,213 \\
R-squared & 0.193 & 0.206 & 0.211 \\
\hline
\end{tabular}




\section{Table A.5}

\section{The increase of credit score and credit behavior}

This table reports estimates from OLS regressions relating credit behavior and subsequent change in credit score. The sample includes homebuyers in the $5 \%$ random sample of the primary-individual data from FRBNY Consumer Credit Panel/Equifax Data. The sample include all homebuyers who purchase their houses at quarter $\tau^{*}$. The dependent variable is an indicator variable that takes on the value of 1 if the credit score increases between $\tau^{*}-4$ and $\tau^{*}$. The credit scores reported here are Equifax risk scores. Negative change of number of credit cards $\geq 75 \%$ credit limit is a dummy that takes on the value of one if there is a decrease in the number of credit cards with balance $\geq 75 \%$ of credit limit from $\left[\tau^{*}-8, \tau^{*}-5\right]$ to $\left[\tau^{*}-4, \tau^{*}-1\right]$. Number of Paid-off Loans $>0$ is one if there is at least one decrease in consumer finance trades in any two consecutive quarters from $\tau^{*}-4$ to $\tau^{*}-1$. Number of Newly Taken Loans $>0$ is one if there is at least one increase in consumer finance trades between any two consecutive quarters from $\tau^{*}-4$ to $\tau^{*}-1$. Reduce Utilization by Reducing Balance and Not Increasing Limit is an indicator variable that takes on the value of one if there is both a negative change in the number of credit cards $\geq 75 \%$ credit limit, a decrease in total credit card balance and a decrease/no change in the total high credit on credit cards from $\left[\tau^{*}-8, \tau^{*}-5\right]$ to $\left[\tau^{*}-4, \tau^{*}-1\right]$. Reduce utilization by other method is one if there is a decrease in the number of credit cards $\geq 75 \%$ credit limit and reduce utilization and not increasing limit is equal to 0 . The controls in all three specification are lagged score distance to closest cutoff above and current credit score bin. Lagged score distance to closest cutoff is a continuous variable that measures the distance in score from the lowest credit score in the period $\left[\tau^{*}-4, \tau^{*}-1\right]$ to the nearest cutoff to move into an improved credit score bin. Control variables include either credit score bin at quarter $\tau^{*}-4$ or the credit score at $\tau^{*}$ and its quadratic form, age, state, and home purchase year fixed effects. Standard errors displayed in parentheses below the coefficient estimates are robust to heteroskedascity and clustered at the state level. ${ }^{*} 10 \%,{ }^{* *} 5 \%,{ }^{* * *} 1 \%$ significance.

\begin{tabular}{lcc}
\hline & $(1)$ & $(2)$ \\
\hline Dependent variable: & Credit score increases from $\tau^{*}-4$ to $\tau^{*}$ \\
\hline (a) \#Newly taken loans $>$ 0 \& \#Paid-off loans $>0$ & $0.0200^{* * *}$ & $0.0182^{* * *}$ \\
& $(0.00330)$ & $(0.00329)$ \\
(b) \#Newly taken loans $=0$ \& \#Paid-off loans $>0$ & $0.0303^{* * *}$ & $0.0301^{* * *}$ \\
& $(0.00323)$ & $(0.00321)$ \\
(c) Reduce utilization without increasing limits & $0.0211^{* * *}$ & $0.0179^{* * *}$ \\
& $(0.00250)$ & $(0.00254)$ \\
(d) Reduce utilization by other method & $0.00845^{* * *}$ & $0.00712^{* * *}$ \\
& $(0.00239)$ & $(0.00239)$ \\
\hline Credit score bin $\left(\tau^{*}-4\right)$ & Yes & No \\
Credit score $\left(\tau^{*}\right)$ and quadratic form & No & Yes \\
Age FE & Yes & Yes \\
State FE & Yes & Yes \\
Home purchase year FE & Yes & 170,597 \\
\hline Observations & 170,597 & 0.047 \\
R-squared & 0.042 & \\
\hline
\end{tabular}

